Article

\title{
Shared Logistic Service for Resilient Agri-Food System: Study of E-Commerce for Local and B2B Markets in Japan
}

\author{
Kaiyuan Lin ${ }^{1,2, * \mathbb{C}}$, Hiroe Ishihara ${ }^{3, * \mathbb{D}}$, Chialin Tsai ${ }^{4}$, Shihhan Hung ${ }^{5}$ and Masaru Mizoguchi ${ }^{1}$ \\ 1 Graduate School of Agricultural and Life Sciences, The University of Tokyo, Tokyo 1138654, Japan; \\ amizo@mail.ecc.u-tokyo.ac.jp \\ 2 Complex Systems Institute of Paris Île-de-France, CNRS, 75013 Paris, France \\ 3 Graduate School of Frontier Sciences, The University of Tokyo, Kashiwa 2778561, Japan \\ 4 College of Art, National Taiwan Normal University, Taipei 106203, Taiwan; 407211211@gapps.ntnu.edu.tw \\ 5 Independent Researcher, Kaohsiung 800, Taiwan; 40647028s@gapps.ntnu.edu.tw \\ * Correspondence: rgpstu15@kmd.keio.ac.jp (K.L.); a-hiroe@g.ecc.u-tokyo.ac.jp (H.I.); \\ Tel.: +81-3-5841-1606 (K.L.); +81-4-7136-4627 (H.I.)
}

check for

updates

Citation: Lin, K.; Ishihara, H.; Tsai, C.; Hung, S.; Mizoguchi, M. Shared Logistic Service for Resilient Agri-Food System: Study of E-Commerce for Local and B2B Markets in Japan. Sustainability 2022, 14, 1858. https://doi.org/10.3390/ su14031858

Academic Editors:

Ching-Cheng Chang and

Witsanu Attavanich

Received: 6 January 2022

Accepted: 4 February 2022

Published: 6 February 2022

Publisher's Note: MDPI stays neutral with regard to jurisdictional claims in published maps and institutional affiliations.

Copyright: () 2022 by the authors Licensee MDPI, Basel, Switzerland. This article is an open access article distributed under the terms and conditions of the Creative Commons Attribution (CC BY) license (https:// creativecommons.org/licenses/by/ $4.0 /)$.

\begin{abstract}
Escalating intensification and homogenization occurring throughout the supply chain poses serious challenges to the global food supply. Several approaches have been developed to shift the food systems to a more resilient path; however, the high unit costs of shipping impede its development. This paper proposes a shared logistic service supported by E-commerce as a solution to this problem. It analyzes the shared logistic system developed by Vegibus Ins. in Japan which has unique features, such as fixed routes. It argues that the logistic service has the ability to connect different scales while supporting flexible transactions leading to the construction of a resilient agri-food system. At the same time, the paper points out the need for subsidies from the governments to facilitate this kind of shared logistic service at the initial stage as one limitation to this approach.
\end{abstract}

Keywords: E-commerce; Japan; local food system; logistics; resilience; sustainable food value chain

\section{Introduction: Challenges in Resilient Agri-Food System}

There is a growing consensus that a transformation is necessary for the global agrifood system to meet various challenges, such as degradation and loss of biodiversity, malnutrition, and rural poverty, which is further aggravated by climate change [1]. The global agri-food system suffers from escalating intensification and homogenization which have been carried out on labor, capital, technology, and ecosystems, transforming the agri-food system into a large monoculture [2]. A specialized but simplified system with a narrow genetic base and taxonomic diversity is fragile when faced with disturbances such as pests, disease outbreaks, and climate change [3]. For example, due to the genetic uniformity of crops, the potato blight epidemic ravaged Ireland in the 1840s, and the cornleaf blight devastated maize production in the USA in the 1970s [4,5]. Enhancing resilience throughout the agri-food system and its supply chain is key to reducing vulnerability towards disturbances, uncertainties, and risks, and to achieve stable food distributions as well as the provision of nutrients.

The notion of resilience, developed by researchers of diverse disciplines, including ecology, engineering, agriculture, and economics, refers to a system's ability to either withstand, absorb, or appropriately respond to disruptions [6-8]. However, there are ongoing debates over the precise definition [9] as it is applied to different fields in a different manner (for a detailed overview of resilience in different fields see [10]).

The literature on the agri-food system, with the outbreak of COVID 19, has witnessed a plethora of studies incorporating the notion of resilience [11-13]. There are multiple definitions of resilience as in other fields, for example, Bullock et al. [14] define resilience in the agri-food system as system's ability to maintain "production of sufficient and nutrient 
food in the face of chronic and acute environmental perturbations"; while Manyise and Dentoni [15], following Costanza et al. [16], define it as the ability to develop organizational arrangement and individual behavior that "continuously balance the trade-offs between the use of natural resource and generation of economic and social benefits" [15]. The common theme that underlies different definitions is the system's capacity to withstand shocks and disturbances. This study, thus, defines a resilient agri-food system as a system with the capacity "to prepare for unexpected events, respond to disruptions and recover from them by maintaining continuity of operations at the desired level of connectedness and control over structure and function" [17].

There are two types of disturbances that agri-food systems need to curtail in order for them to remain resilient, namely, demand and supply uncertainty [18]. Demand uncertainty refers to disturbances that affect the consumer's willingness to purchase certain products, such as price fluctuation due to a change in the subsidy policy, while supply uncertainty refers to a disturbance that affects the producer's willingness to produce certain goods, such as high frequency of droughts or pests [19]. These disturbances can originate from within and outside of the agri-food system [20].

In order to curtail these uncertainties, the literature focuses on two aspects of resilience, i.e., maintaining diversity and redundancy and managing connectivity [19]. Maintaining diversity and redundancy provide us with a substitute when faced with disturbance, such as producing different varieties of potato to curtail supply uncertainty in the occurrence of a potato epidemic by allowing farmers to sell potatoes that are resistant to the epidemic. Management of connectivity, such as establishing roads or traceability systems, facilitates the flow of goods as well as information, which is critical for both managing supply and demand uncertainty. For example, a traceability system with higher cost-effectiveness, accuracy, user-friendliness, and security has been developed to enhance resilience [21]. Hodbod and Eakin [22], further argue that the management of scales is important for a resilient agri-food system. Disturbances created at a local scale are often transmitted across different scales. For example, the bad harvest of one agricultural product at one local scale may affect the global availability of the product, resulting in a surge in global price.

Several approaches have been developed to shift the agri-food systems to a resilient path such as local food systems [23], and decentralization [24]. For example, Schipanski et al. [23] argue that local food systems enhance resilience through increasing the connectivity between producers and buyers through geographical proximity. This allows buyers to identify social and ecological costs associated with food production, often 'masked, diluted and drowned out' in the conventional supply chain [25]. In the local food system, consumer behavior is determined not just by price signals but also by different information, such as how it was produced and by whom.

However, some research shows that the local food system through direct sale is stagnated, while the local food system through intermediaries is becoming more popular [26,27]. Richards et al. [27], who studied the US local food systems, argue that it is more convenient for consumers to purchase a variety of goods on one purchase occasion, i.e., local food as well as other products, making the direct sale unpopular. Locally sourced foods are becoming more and more available in nationwide supermarket chains such as Wegmans, Whole Foods, and Walmart. The high fixed cost of logistics of direct sales, such as maintaining large warehouses and transportation routes, is further diverting the buyers away from the direct sales of local food [28].

The same trend can be observed in Japan [29]. In this study, we conducted a case study of Vegibus, which provides a logistic service to distribute local foods from Business to Business (B2B) in Japan. It connects small-scale farmers, who are the majority of farmers in Japan [30], and retailers, such as local restaurants and supermarkets. We argue that the Vegibus contributes to the establishment of a resilient agri-food system in Japan by (i) enhancing the connectivity between producers and buyers, (ii) providing choice variety, and (iii) lowering the unit cost of distribution per product. 
This study is structured as follows: Section 2 elaborates on the services required to construct a resilient agri-food system in detail. Section 3 introduces the case of Vegibus and evaluates how its unique logistics service is contributing to the choice variety for buyers and is suppressing the cost of distribution. Finally, Section 4 discusses the possibilities and limits of Vegibus service through comparisons with another type of local food system using intermediation.

\section{Concept: Services to Consolidate Local Food Systems and Resilience}

As discussed above, one of the main predicaments of constructing a resilient agrifood system is reducing unit costs of production while maintaining diversity, redundancy, and connectivity. In order to overcome this predicament, this section describes the two conditions of services required for a resilient agri-food system; (i) achieving economies of scale while maintaining the flexibility of transaction between producers and buyers and (ii) sharing the logistics service among the producers and the buyers.

Economies of scale are the underlying drivers that determine the unit costs of production [31]. Furthermore, through scaling up it is possible to increase the visibility of local food which is often considered as one of the major impediments in constructing a resilient agri-food system. Faced with unfamiliar products, new ingredients, or even simply new sources, buyers often avoid purchasing them unless they are sold at very low prices or other incentives to buy these unfamiliar products are presented, which stagnates the ability of local food to penetrate the mainstream markets [32].

Digitalization is one way to scale up production while retaining the flexibility of transactions. Digitalizing services with integrated information, such as E-commerce [33], provide flexible transaction between producers and buyers and facilitate the local food to penetrate the B2B market. These services, firstly, provide the producers with the ability to manage supply chain processes through more accessible sales forecasts and production data, thus, reducing the demand uncertainty for producers [34-36]. Secondly, they allow buyers to access information on social and ecological costs associated with food production, thereby allowing the buyers to make an ethical choice upon purchase [25]. Thirdly, they contribute to a reduction in food mileage, by facilitating direct trade between producers and buyers [35,37]. Fourthly, digitalized services integrate the often fragmented and complex local food systems, functioning as an intermediary in the B2B market by connecting smallscale local food producers to various buyers including large retailers [36,38].

Nevertheless, the adoption of these digitized services is, often, not feasible among small to middle-scale business owners owing to their poor capital. In the agri-food system, digitalization has special challenges as its supply chains require multiple facets such as production, transportation, processing, packaging, retailing, and recycling while meeting various safety standards, issuing the export declaration, and managing orders, raising the cost of digitalization. To reduce the costs of these services, a shared mechanism is required, leading us to the second requirement for the resilient agri-food system.

\section{Shared Logistic Service for Direct Trade}

This section elaborates on a shared logistic service developed by Vegibus Inc. (hereafter, Vegibus) (Figure 1), which runs fixed bus routes from production to consumption sites to distribute local food in Japan. Vegibus is chosen as a case study as its services help the producers and the buyers to avoid contracting warehouse facilities which are used in the conventional supply chain [39], thereby reducing the unit costs of production. This is in contrast to the conventional supply chain where products will first be collected from the production field to the auction market and then distributed back to the production field. Furthermore, its services combine ordering E-commerce with the sophisticated Electronic Retailing System (ERS) and transportation shared-logistic service. Vegibus, currently, operates 15 routes across Japan covering nine prefectures (as of 31 October 2021) and targets B2B buyers such as restaurants, supermarkets, or group purchases in a community for a higher order quantity. 


\section{Vegibus E-commerce}

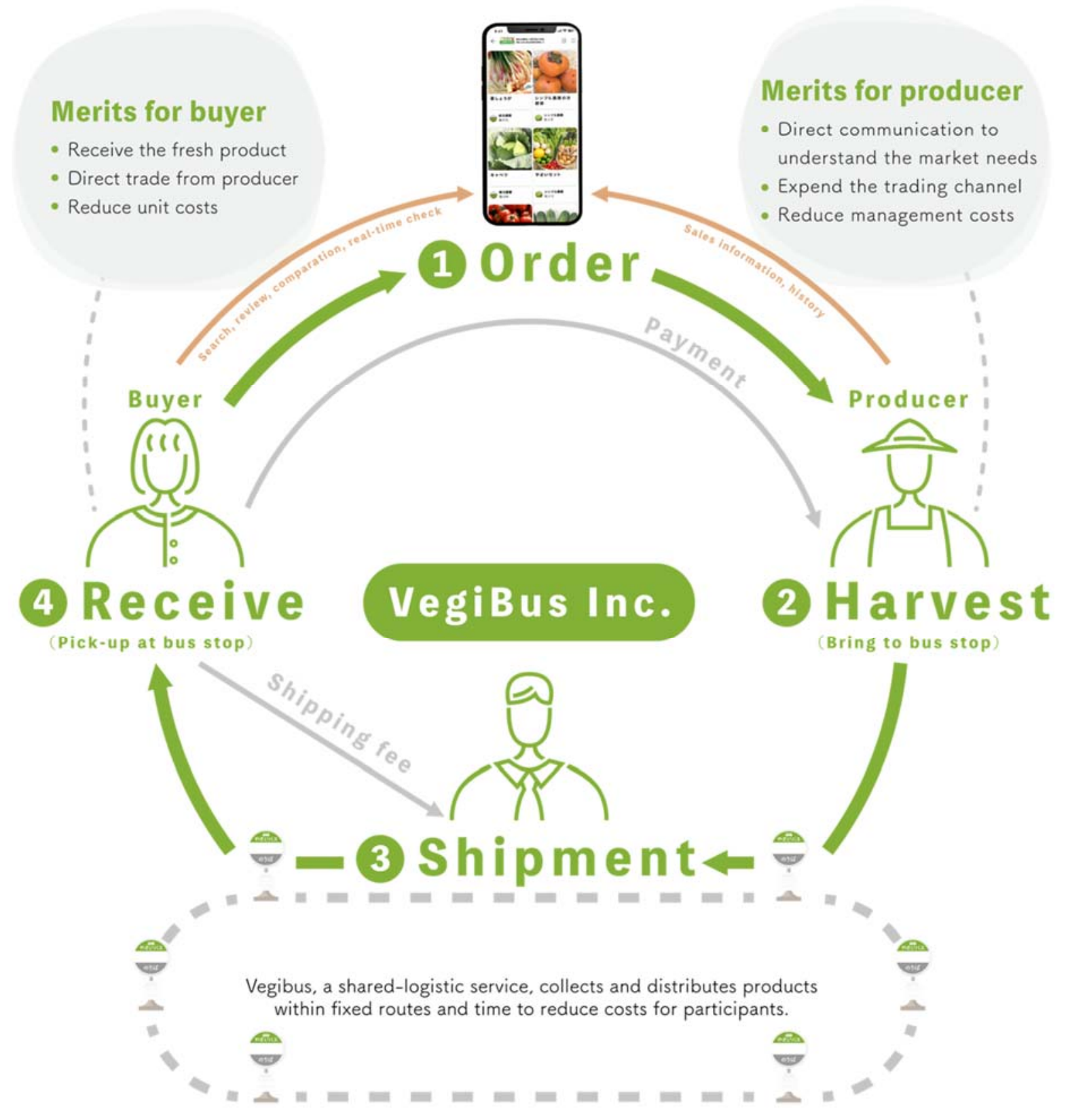

Figure 1. Vegibus' Service Model.

In the following section the uniqueness of Vegibus is described in detail. In Vegibus, the supply chain is divided into the most basic units, namely producer, buyer, and logistic service. The uniqueness of this service is three-fold; i) fixed route and time, ii) shipment from one container and iii) B2B E-commerce and management services.

\subsection{Fixed Route and Time to Reduce the Unit Cost}

Vegibus operates along fixed routes and has recruited places to serve as bus stops for collection and pickup points. Producers bring their products to the nearest bus stop by a certain time of the day, while buyers pick up their ordered products from the bus stop they reserved beforehand. They are also free to attend at any time they wish to pick up their product after the delivery time. Furthermore, the service guarantees same-day delivery as long as the product and the buyer are in the same prefecture. It frees Vegibus from 
building a large warehouse and exclusive transportation service as done by conventional supply chains; at the same time, it allows the buyer to have a precise calculation of the food mileage and assurance of traceability.

\subsection{Shipment from One Container}

Vegibus has a standardized container (Weight + Height + Depth $=120 \mathrm{~cm}$ ) which can be filled with different products. It allows the buyers to put diverse products in one container, allowing for a flexible transaction for both buyers and producers while minimizing the unit costs of shipment. The buyers can order from one container as Vegibus only charges shipping costs determined by the number of ordered containers. From the producers' point of view, Vegibus allows them to set a minimum order quantity and price for each product depending on their preferences, reducing demand uncertainty.

\subsection{B2B E-Commerce and Management Services}

The shared logistic service in Vegibus has a supportive E-Commerce (EC) site which connects the producers and buyers. The service encompasses the function of the electronic retailing system (ERS) from transaction1, communication, payment, feedback to customer management. Through this service, producers and buyers are able to communicate directly, and manage orders. Its EC site assists the producers in conveying various information other than price and minimum quantity of order, such as production time, product category, place of origin, estimated shipping date, and estimated production volume, to their potential buyers, reducing the supply uncertainty which may deter buyers from purchasing local food. This connectivity between buyers and producers, on one hand, encourages the producers to cooperate with small-scale orders starting from one container, and on the other hand, encourages the buyers to purchase unfamiliar products in the local food system.

\section{Methods and Result}

\subsection{Methods}

This section analyzes orders in the Vegibus from 1 January 2019 to 31 October 2021. Data were collected through the production database in the Vegibus server. A total of 48,326 orders remained after conditions such as limited-time events or routes and joint shipments were accounted for. To analyze Vegibus' ability to connect different order scales and to provide flexible transactions between the producers and buyers, this section scrutinizes the order number per day, the container amount, and the space utilization of containers. The section excluded orders that have any missing data in the database fields which are caused by reasons such as a revised order and deletion due to delay in delivery, leaving 38,492 orders for analysis.

Secondly, to analyze Vegibus' ability to reduce the unit cost of shipment by the fixed route and shared logistics in a specific region, the section compares the average required miles per order under the following two conditions: with and without Vegibus. To perform this task, orders were excluded from the data if i) the registered addresses of producers or buyers were not correctly displayed in latitude and longitude, and ii) the registered addresses of producers and buyers were not in the same prefecture, leaving 29,450 orders for analysis. For conditions without Vegibus, the distance between producers and buyers was calculated in linear distance. It uses the latitude and longitude of producers' and buyers' addresses to calculate distance and analyzes the way food mileage changes as the number of orders increased.

\subsection{Ability to Connect Different Order Scales and Provide Flexible Transaction}

Figure 2 shows the number of orders buyers placed in a day and also the number of containers they purchased per order. It shows that $71 \%$ of buyers place less than five orders per day and that $80 \%$ of orders are of less than three containers. The majority of buyers are small-scale businesses that place a small number of orders, of one to three containers per day. However, at the same time, some of the buyers placed an order of 500 containers. This 
shows that the Vegibus' logistic service has the ability to cater to both large and small-scale businesses, providing flexible transactions and connecting different scales.

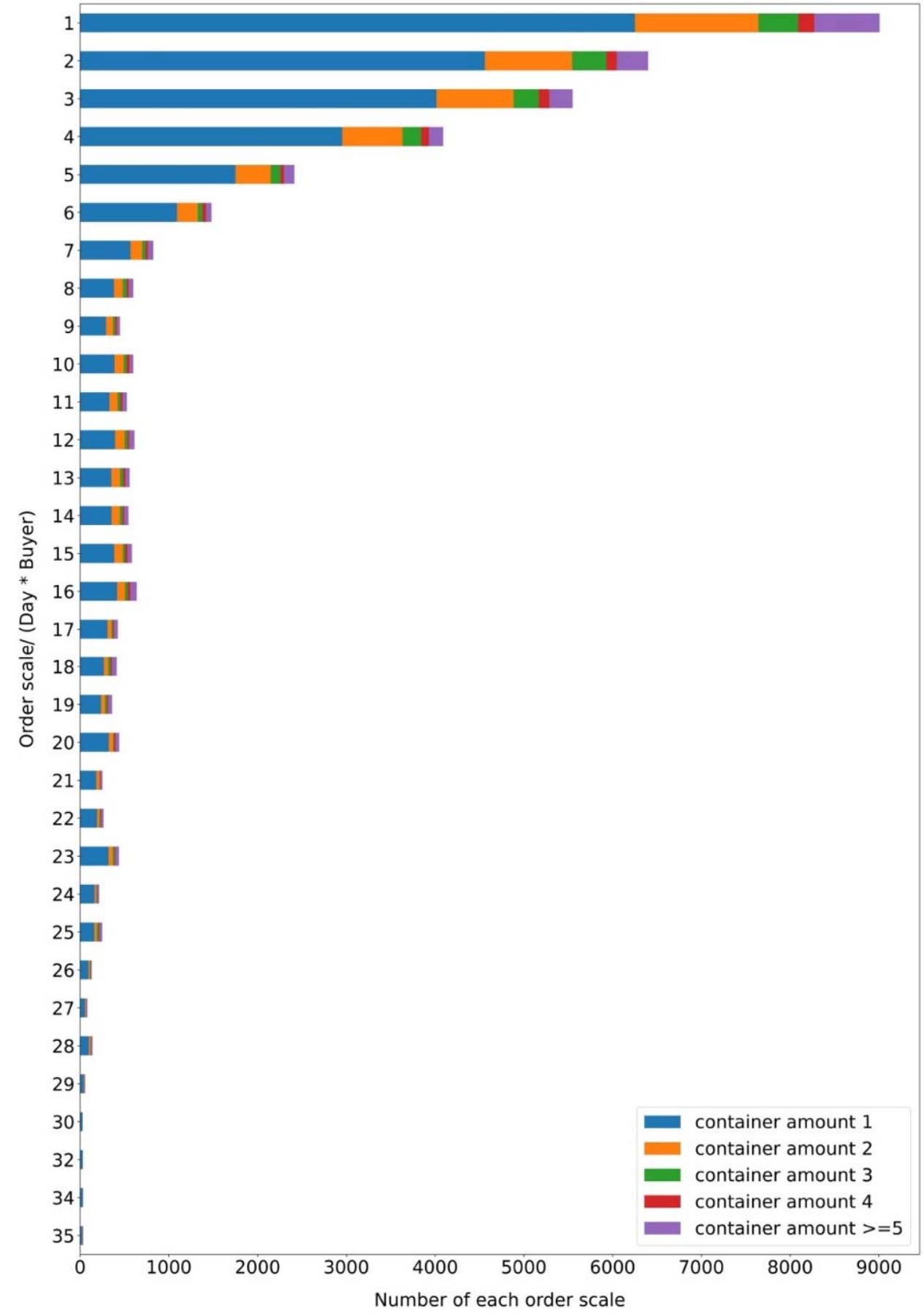

Figure 2. Evaluation of order scales. X-axis presents a number of each order scale, Y-axis presents order scale per day per buyer (an order may include multiple products), and colors in each bar represent different container amounts included in that order scale.

In Vegibus, the producers must reveal the space utilization of containers, i.e., the percentage that the products occupy in the container, and the rule for a single order is to fill one container before moving on to the next. The correlation between purchase and packing can be shown by the space utilization of the last container. Figure 3 shows the space utilization of containers. It shows that $40.8 \%$ of orders achieved $100 \%$ space utilization while orders with $80 \%$ or $90 \%$ space utilization were much fewer. This reveals that most of 
the buyers tend to make the best effort to fill the containers to reduce unit costs, which will in turn stimulate further purchase (per order).

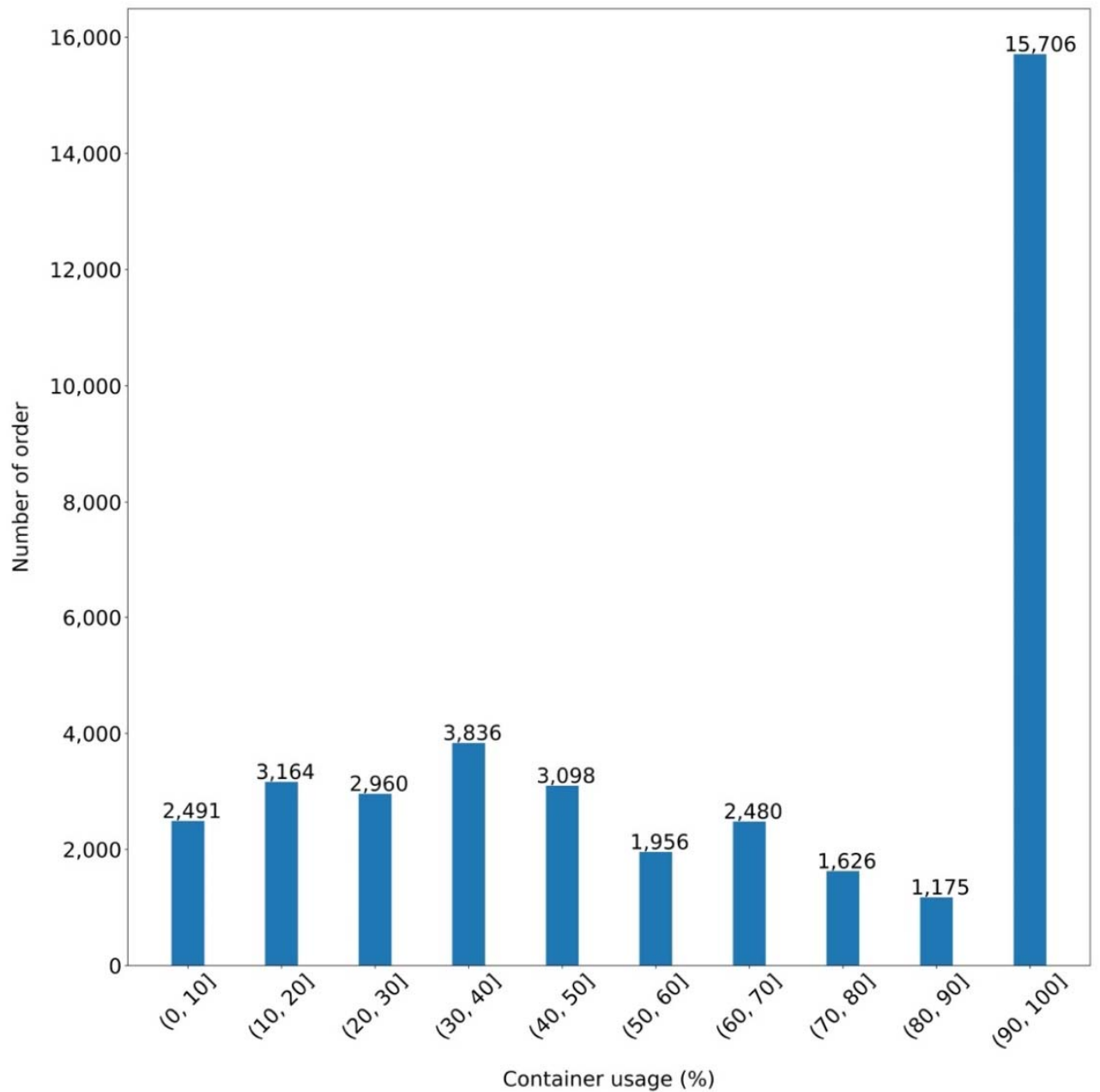

Figure 3. The space utilization of the last containers per order. $X$-axis presents the space utilization of the last container. The space utilization is divided into 10 intervals. Among them, $100 \%$ means the space utilization of the last container is $90 \%<X<=100 \%$, and 90 means that it is $80 \%<X<=90 \%$, etc. Y-axis presents the total number of orders for space utilization.

\subsection{Ability to Reduce the Distance Per Shipment}

In this section, we compare the required distance for the Vegibus route for a single order (the blue bar) and the average required miles for a conventional transportation system (representing the condition without the Vegibus) (the orange bar). Shipping miles are used as evidence to illustrate why regionally shared logistics, such as those in the Vegibus, can reduce shipping costs for a single order compared to conventional logistics, with consolidated shipping and non-fixed routes adjusted according to the different locations of buyers.

Figures 4-8 show that without a shared logistic service, one shipment requires an average of 10 to 40 miles, whereas with shared logistic services the distance per one shipment is significantly reduced if there are more than four to eight orders per route. For example, in the Shizuoka route1 (as shown in Figure 4), when the order exceeds six, we can see that the distance per shipment under regionally shared logistic service is less than that of the shipment without a shared-logistic service. 


\section{- Shizuoka route 1}

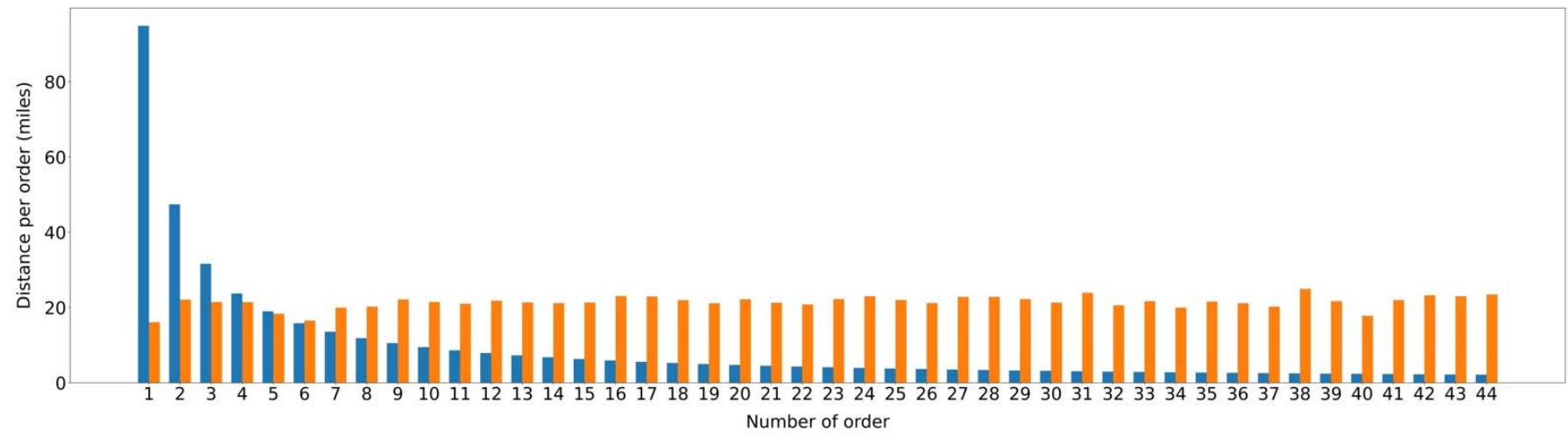

Figure 4. Shizuoka route 1. X-axis presents a number of orders per day which happened before in this route, Y-axis presents the average distance per order.

\section{- Shizuoka route 2}

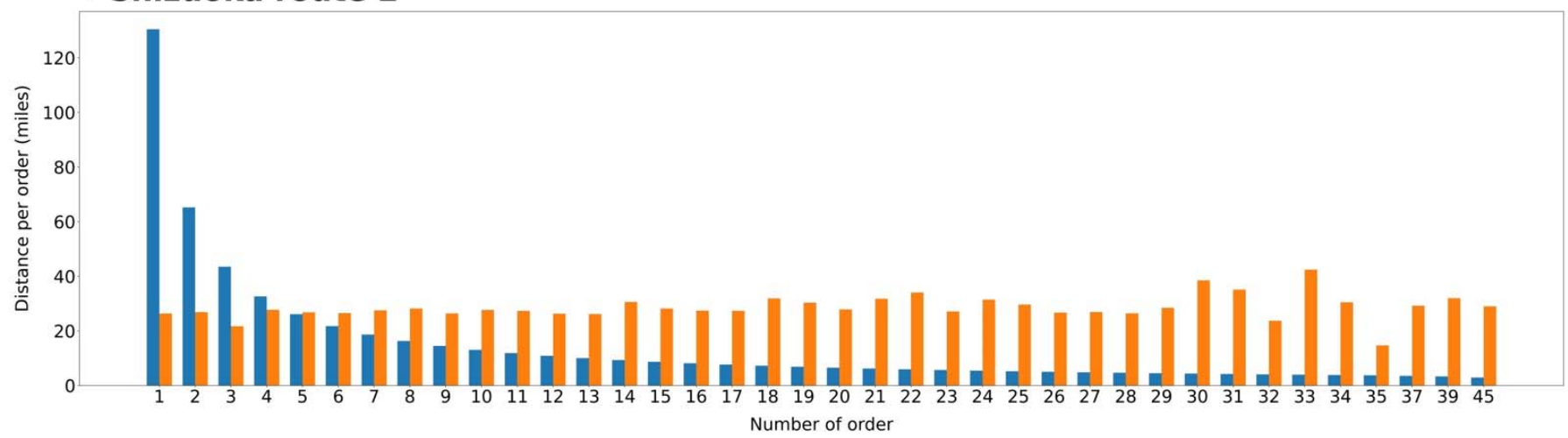

Figure 5. Shizuoka route 2. X-axis presents the number of orders per day which happened before in this route, $\mathrm{Y}$-axis presents the average distance per order.

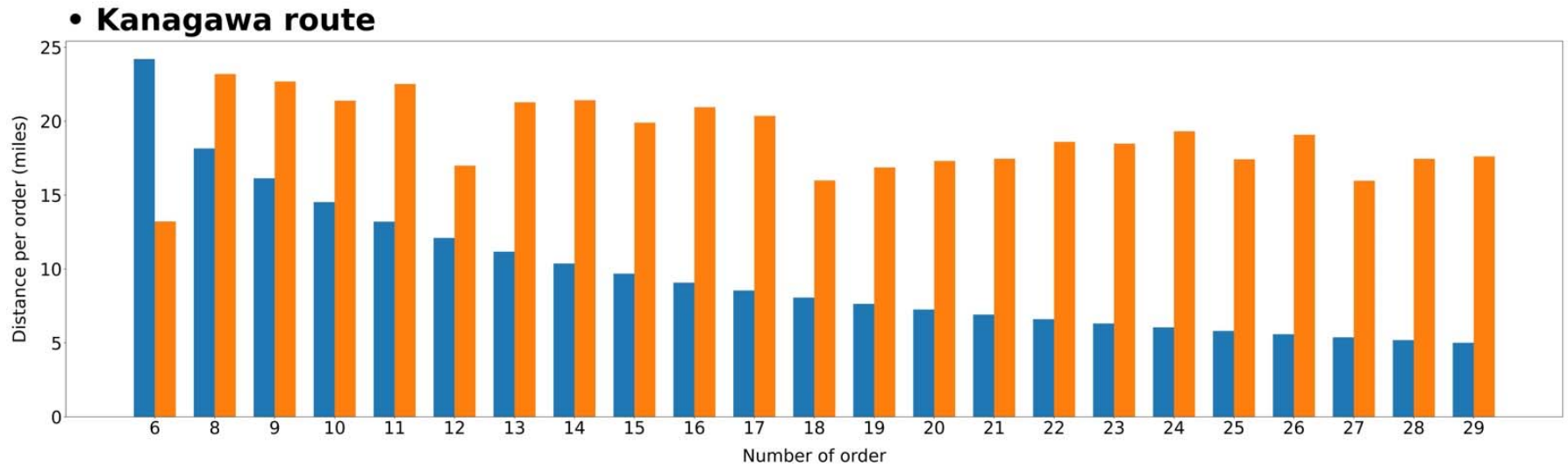

Figure 6. Kanagawa route. $X$-axis presents a number of orders per day which happened before in this route, Y-axis presents the average distance per order.

The description and result of each route are illustrated as follows: Figure 4 presents the results of Shizuoka route 1, which shipped a total of 12,915 orders and traded 1996 different types of products from 1 January 2019 to 3 October 2021. A total of 94.9 miles are required to operate this route thoroughly. In the case of only one order being shipped per day, the Vegibus requires an average of 94.9 miles, while without the use of Vegibus, 16.1 miles are required. In the case of six orders being shipped per day, the distance per order of Vegibus is significantly lowered compared to the case without Vegibus. In the case of 44 orders per day, the maximum in this route, the Vegibus requires an average of 2.2 
miles per shipment, while the case without Vegibus requires 23.5 miles. A similar trend can be observed in the Shizuoka route (show in Figure 5), the Kanagawa route (shown in Figure 6), the Ibaraki route (shown in Figure 7), and the Chiba route (shown in Figure 8).

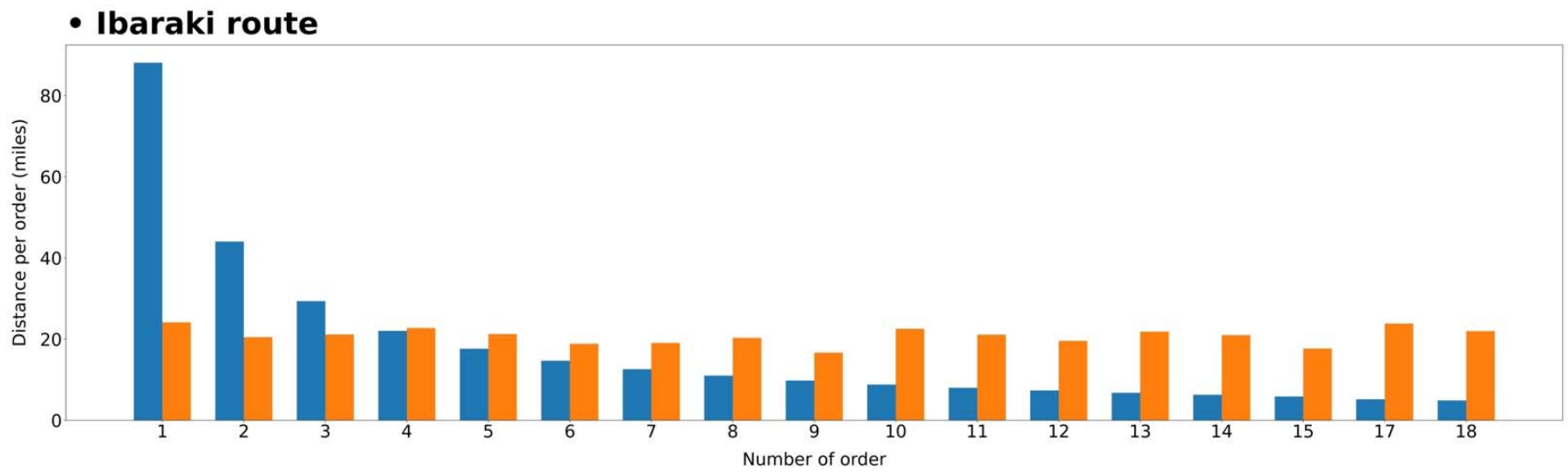

Figure 7. Ibaraki route. $\mathrm{X}$-axis presents a number of orders per day which happened before in this route, $\mathrm{Y}$-axis presents the average distance per order.

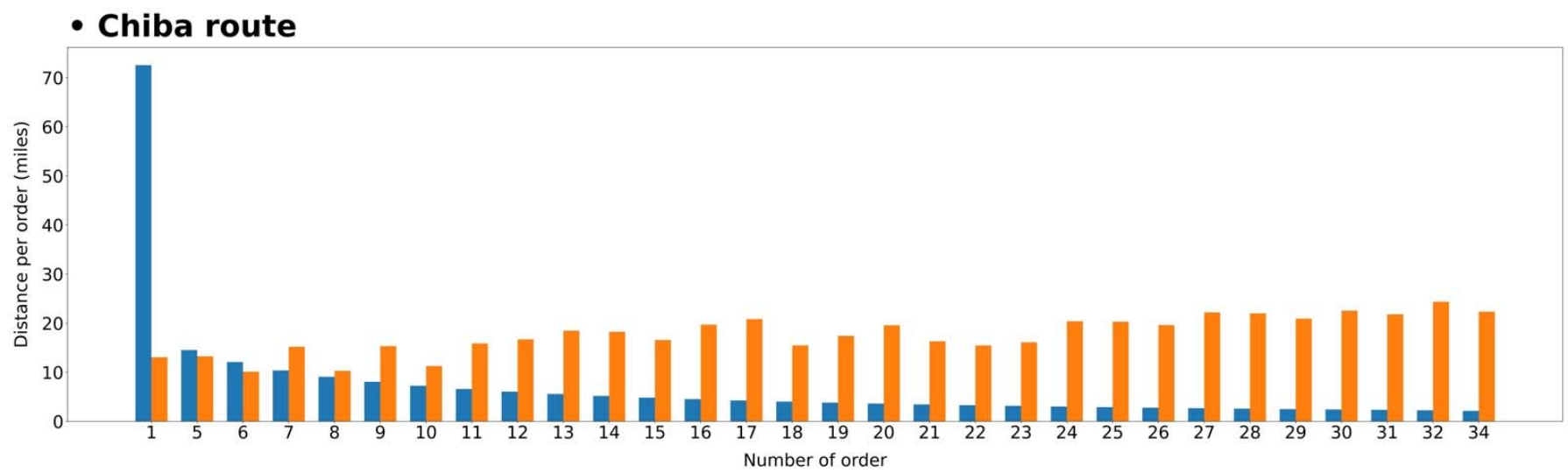

Figure 8. Chiba route. $X$-axis presents a number of orders per day which happened before in this route. Y-axis presents the average distance per order.

\section{Discussion}

The previous section, by analyzing the order data extracted from the database, has shown that Vegibus' shared logistic service has the ability to connect different order scales as it allows the buyers to purchase between one container and 500 containers, and to reduce the mile per shipment as it uses a fixed route for the distribution of its products. This section discusses how Vegibus contributes to a resilient agri-food system by comparing it with other local food systems while stating the potential limits of the Vegibus' shared logistic service.

\subsection{Vegibus as Resilient Agri-Food System}

This section discusses how Vegibus contributes to two aspects of resilience, i.e., maintaining diversity and redundancy, and managing connectivity. Under the current Vegibus shared-logistic service, the producers can set the price as they wish. This ensures the resource sovereignty of producers to a certain extent and thereby creates a buffer against demand and supply uncertainties such as price volatility and supply interruptions. The promotion of diversity can be further supported by the results presented in Figures 4-8 which show that a variety of products are traded in different routes. In terms of managing connectivity, an integrated EC platform constructs direct communication between producers and buyers. Buyers are able to review product information and the delivery time 
beforehand, and thus they are able to manage sales plans. It allows buyers to purchase various products through direct trade instead of relying on one purchase occasion. As for producers, they are able to receive real-time feedback from the market to reconstruct and adjust the production plan. Furthermore, due to fixed routes, clear traceability can be provided in Vegibus. These symmetric information exchanges between the buyers and producers can forge trust and commitment to each other, further reducing supply and demand uncertainty [40].

According to the literature on the "local food system", there are two types of the supply chain used by this system, (i) direct-to-retail and (ii) direct-to-consumer [41]. We compared two aspects of resilience as mentioned above and three aspects related to local food systems, namely, producer-buyer selling arrangement [42,43], producer-consumer interaction [44,45], and proximity, which are further categorized into three domains as follows: geographical proximity (e.g., physical locality, the distance between the food production site and consumption site), relational proximity (e.g., close relationship between the buyers and the producers within the agri-food system) and proximity in values (e.g., place of origin, traceability, freshness, quality [46].

Vegibus is not a direct-to-consumer platform as the majority of buyers are small-scale retailers, although there are some community purchases. It is a B2B platform allowing for a much larger bulk of products to be traded, compared to B2C, which may assist in the market penetration of certain products. At the same time, it is different from direct-to-retail as it does not require the producers and the buyers to have any type of contract, allowing for a flexible transaction to occur between them. Vegibus provides an online ordering platform that allows the buyers and the producers to engage in their transactions. Furthermore, it allows diverse products to be traded through this system as it is not restricted to a certain region or specific schemes such as organic trade as in many other local food systems. Additionally, its services from shelves, purchases, to logistics are open to entities instead of being limited to specific groups. The characteristics of these three types of the local food system are summarized in Table 1.

Table 1. Comparison between Vegibus and other local food systems.

\begin{tabular}{cccr}
\hline Type of Local Food System & $\begin{array}{c}\text { Direct-to-Retail Restaurant } \\
\text { Institution Local } \\
\text { Independent Rerailers }\end{array}$ & $\begin{array}{c}\text { Direct-to-Consumer } \\
\text { Community- } \\
\text { Supported Agriculture }\end{array}$ & Regibus \\
\hline Management of connectivity & Relational trading & Low trading & Clear traceability \\
\hline $\begin{array}{c}\text { Maintaining diversity } \\
\text { and redundancy }\end{array}$ & Low & Formal contract & EC platform integrated \\
\hline $\begin{array}{c}\text { Producer-buyer } \\
\text { selling arrangement }\end{array}$ & $\begin{array}{c}\text { Relational contract; formal } \\
\text { contract }\end{array}$ & Face-to-face; proximate & No contract needed \\
\hline Producer- consumer interaction & proximate & Relational & Geographical values \\
\hline Domains of proximity & Geographical & High & Low \\
\hline Consumer Commitment & Low & B2C & B2B \\
\hline Business type & B2B & Order & Order; E-commerce; logistics \\
\hline Key supply chain services & Order & & Thate \\
\hline
\end{tabular}

B2B: business to business; B2C: business to consumer.

\subsection{Possibilities and Limits}

The results show that Vegibus' shared logistic service contributes to enhancing their resilience by mitigating supply and demand uncertainty. However, some limitations must be mentioned. Firstly, demand uncertainty, to a certain extent, continues to exist for the producers as there is no minimum mandatory trading volume per order for the buyers. Under the current system, the buyers can order just one container, leading to a small trading volume and less visibility in the market. One way to cope with this challenge is to reinforce the management service of the supply chain between producers and buyers to augment 
the number of users, usage rate, and order scales, reaching the same trading volume and visibility to that of a conventional supply chain.

Secondly, the products distributed through the Vegibus logistic service have faced fierce price competition with other products distributed through different systems. As a pure logistics platform, Vegibus did not initially engage in marketing. Therefore, the service needs to put more emphasis on highlighting the uniqueness and distinctiveness of products. For example, clearly labeling food mileage or providing a pathway for exclusive products can support local food. Furthermore, the ongoing collaboration with the Japan railway company can extend the usability of bus stops to serve as selling sites.

Lastly, the cost of establishing a new bus route is another constraint for an agri-food system such as Vegibus. To establish a new route, Vegibus undertakes multiple local negotiations and communications with local stakeholders, which are time-consuming as well as financially costly. Currently, these transaction costs are covered by subsidies from the central and local governments. High transaction costs are an inevitable problem for shared logistic services or shared logistic systems but can be solved over time as Vegibus begins to turn a profit. To this end, this can be considers as both the limit and the possibility of Vegibus to tackle the issue of diversity and complexity.

\section{Conclusions}

Ever-increasing uncertainties in global food supply have heightened the urgent demand for a resilient agri-food system. However, the high unit costs are key obstacle for constructing a resilient agri-food system. This study proposes shared logistic services such as Vegibus as a way to overcome this challenge, through B2B E-commerce with flexible transactions. Vegibus can adapt to both small and large-scale orders, showing the possibility of achieving economies of scale to reduce unit costs, while retaining flexibility in a transaction. Furthermore, by the fixed-route of shared logistic service, Vegibus is able to reduce the food mileage, while solidifying the traceability of products. In addition, Vegibus's integrated EC platform encourages direct trade between producers and buyers by forging trust and commitment to each other. With these benefits, Vegibus is considered as one way to construct a resilient agri-food system despite its limitations.

Author Contributions: Conceptualization, K.L. and H.I.; methodology, K.L. and S.H.; formal analysis, K.L. and S.H.; writing-original draft preparation, K.L. and C.T.; writing-review and editing, H.I. funding acquisition, M.M. All authors have read and agreed to the published version of the manuscript.

Funding: This research received no external funding.

Data Availability Statement: Not applicable.

Acknowledgments: We would like to express our gratitude to Yuriko Kato and Vegibus Inc. for sharing the information and wisdom with us. The research environment was provided and supported by two institutions, Graduate School of Agricultural and Life Sciences, The University of Tokyo, and College of Art, National Taiwan Normal University.

Conflicts of Interest: The authors declare no conflict of interest.

\section{References}

1. Wezel, A.; Herren, B.G.; Kerr, R.B.; Barrios, E.; Gonçalves, A.L.R.; Sinclair, F. Agroecological principles and elements and their implications for transitioning to sustainable food systems. A review. Agron. Sustain. Dev. 2020, 40, 1-13. [CrossRef]

2. Hamilton, H.; Henry, R.; Rounsevell, M.; Moran, D.; Cossar, F.; Allen, K.; Boden, L.; Alexander, P. Exploring global food system shocks, scenarios and outcomes. Futures 2020, 123, 102601. [CrossRef] [PubMed]

3. van de Wouw, M.; van Hintum, T.; Kik, C.; van Treuren, R.; Visser, B. Genetic diversity trends in twentieth century crop cultivars: A meta analysis. Theor. Appl. Genet. 2010, 120, 1241-1252. [CrossRef] [PubMed]

4. Baeza Lopez, P. A New Plant Disease: Uniformity; FAO: Rome, Italy, 1994.

5. Malysheva-Otto, L.; Ganal, M.W.; Law, J.R.; Reeves, J.C.; Röder, M.S. Temporal trends of genetic diversity in European barley cultivars (Hordeum vulgare L.). Mol. Breed. 2007, 20, 309-322. [CrossRef] 
6. Folke, C.; Biggs, R.; Norström, A.V.; Reyers, B.; Rockström, J. Social-ecological resilience and biosphere-based sustainability science. Ecol. Soc. 2016, 21, 21. [CrossRef]

7. Berkes, F.; Folke, C. Linking Social and Ecological Systems for Resilience and Sustainability, Beijer International Institute of Ecological Economics, The Royal Swedish. Available online: https://hdl.handle.net/10535/4352 (accessed on 4 January 2022).

8. Holling, C.S. Engineering resilience versus ecological resilience. Eng. Ecol. Constraints 1996, 31, 32. Available online: https: //www.nap.edu/catalog/4919/engineering-within-ecological-constraints (accessed on 4 January 2022).

9. Newton, A.C. Biodiversity Risks of Adopting Resilience as a Policy Goal. Conserv. Lett. 2016, 9, 369-376. [CrossRef]

10. Bhamra, R.S.; Dani, S.; Burnard, K.J. Resilience: The concept, a literature review and future directions. Int. J. Prod. Res. 2011, 49, 5375-5393. [CrossRef]

11. Coopmans, I.; Bijttebier, J.; Marchand, F.; Mathijs, E.; Messely, L.; Rogge, E.; Sanders, A.; Wauters, E. COVID-19 impacts on Flemish food supply chains and lessons for agri-food system resilience. Agric. Syst. 2021, 190, 103136. [CrossRef]

12. Heck, S.; Campos, H.; Barker, I.; Okello, J.J.; Baral, A.; Boy, E.; Brown, L.; Birol, E. Resilient agri-food systems for nutrition amidst COVID-19: Evidence and lessons from food-based approaches to overcome micronutrient deficiency and rebuild livelihoods after crises. Food Secur. 2020, 12, 823-830. [CrossRef]

13. Mussell, A.; Bilyea, T.; Hedley, D. Agri-food supply chains and covid-19: Balancing resilience and vulnerability. Agri. Food Econ. Syst. 2020, 1-6. Available online: http:/ /www.agrifoodecon.ca/uploads/userfiles/files/agri-food\%20supply\%20chains\% 20and $\% 20$ covid-19\%20mar\%2022-20(1).pdf.

14. Bullock, J.M.; Dhanjal-Adams, K.; Milne, A.; Oliver, T.H.; Todman, L.; Whitmore, A.; Pywell, R.F. Resilience and food security: Rethinking an ecological concept. J. Ecol. 2017, 105, 880-884. [CrossRef]

15. Manyise, T.; Dentoni, D. Value chain partnerships and farmer entrepreneurship as balancing ecosystem services: Implications for agri-food systems resilience. Ecosyst. Serv. 2021, 49, 101279. [CrossRef]

16. Costanza, R.; de Groot, R.; Sutton, P.; van der Ploeg, S.; Anderson, S.J.; Kubiszewski, I.; Farber, S.; Turner, R.K. Changes in the global value of ecosystem services. Glob. Environ. Change 2014, 26, 152-158. [CrossRef]

17. Ponomarov, S.Y.; Holcomb, M.C. Understanding the concept of supply chain resilience. Int. J. Logist. Manag. 2009, 20, 124-143. [CrossRef]

18. Chopra, S.; Meindl, P.; Kalra, D.V. Supply Chain Management: Strategy, Planning, and Operation; Pearson: Boston, MA, USA, 2013; Available online: https:/ /www.iuj.ac.jp/gsim-f/im-info/syllabus/2015S/OPR4150Li.pdf (accessed on 4 January 2022).

19. Vroegindewey, R.; Hodbod, J. Resilience of Agricultural Value Chains in Developing Country Contexts: A Framework and Assessment Approach. Sustainability 2018, 10, 916. [CrossRef]

20. Christopher, M.; Peck, H. Building the Resilient Supply Chain. Int. J. Logist. Manag. 2004, 15, 1-14. [CrossRef]

21. Nishantha, G.; Wanniarachchige, M.; Jehan, S. A pragmatic approach to traceability in food supply chains. In Proceedings of the 12th International Conference on Advanced Communication Technology (ICACT), Gangwon-Do, Korea, 7-10 February 2010.

22. Hodbod, J.; Eakin, H. Adapting a social-ecological resilience framework for food systems. J. Environ. Stud. Sci. 2015, 5, 474-484. [CrossRef]

23. Schipanski, M.E.; MacDonald, G.; Rosenzweig, S.; Chappell, M.J.; Bennett, E.M.; Kerr, R.B.; Blesh, J.; Crews, T.; Drinkwater, L.; Lundgren, J.G.; et al. Realizing Resilient Food Systems. Bioscience 2016, 66, 600-610. [CrossRef]

24. Jacobi, J.; Mukhovi, S.; Llanque, A.; Augstburger, H.; Käser, F.; Pozo, C.; Peter, M.N.; Delgado, J.M.F.; Kiteme, B.P.; Rist, S.; et al. Operationalizing food system resilience: An indicator-based assessment in agroindustrial, smallholder farming, and agroecological contexts in Bolivia and Kenya. Land Use Policy 2018, 79, 433-446. [CrossRef]

25. I Crona, B.; Daw, T.M.; Swartz, W.; Norström, A.; Nyström, M.; Thyresson, M.; Folke, C.; Hentati-Sundberg, J.; Osterblom, H.; Deutsch, L.; et al. Masked, diluted and drowned out: How global seafood trade weakens signals from marine ecosystems. Fish Fish. 2015, 17, 1175-1182. [CrossRef]

26. Mcfadden, D.T. What do we mean by "local foods". Choices 2015, 30, 1-6. Available online: https://www.jstor.org/stable/choices. 30.1.02 (accessed on 4 January 2022).

27. Richards, T.J.; Hamilton, S.F.; Gomez, M.; Rabinovich, E. Retail Intermediation and Local Foods. Am. J. Agric. Econ. 2017, 99, 637-659. [CrossRef]

28. Satomura, M.; Moritaka, M.; Fukuda, S. A study on the positioning of the farmers' markets and supermarkets as retail formats. Agric. Mark. J. Jpn. 2014, 23, 23-33. (In Japanese)

29. Smith, H.; Øyvind, T. Multi-category demand and supermarket pricing. Int. J. Ind. Organ. 2012, 30, 309-314. [CrossRef]

30. Ministry of Agriculture Forestry and Fisheries, 2020 agricultural-forestry census 2021. (In Japanese). Available online: https: / www. maff.go.jp/j/tokei/census/afc/ (accessed on 4 January 2022).

31. Khemani, R.S.; Shapiro, D.M. Economics of scale. Glossary of Industrial Organisation Economics and Competition Law; OECD Publications and Information Centre: Washington, DC, USA, 1993. Available online: https://www.oecd.org/competition/ publicationsdocuments/glossary/ (accessed on 4 January 2022).

32. Clemons, E.K. How Information Changes Consumer Behavior and How Consumer Behavior Determines Corporate Strategy. J. Manag. Inf. Syst. 2008, 25, 13-40. [CrossRef]

33. Harland, C.; Caldwell, N.; Powell, P.; Zheng, J. Barriers to supply chain information integration: SMEs adrift of eLands. J. Oper. Manag. 2007, 25, 1234-1254. [CrossRef] 
34. Turban, E.; Outland, J.; King, D.; Lee, J.K.; Liang, T.-P.; Turban, D.C. Electronic Commerce 2018: A Managerial and Social Networks Perspective; Springer: Berlin/Heidelberg, Germany, 2018.

35. Snow, C.C.; Fjeldstad, Ø.D.; Lettl, C.; Miles, R.E. Organizing Continuous Product Development and Commercialization: The Collaborative Community of Firms Model. J. Prod. Innov. Manag. 2010, 28, 3-16. [CrossRef]

36. Schrauf, S.; Berttram, P. Industry 4.0: How digitization makes the supply chain more efficient, agile, and customer-focused. Strateg. Technol. 2016, 1-32. Available online: https://www.strategyand.pwc.com/gx/en/insights/2016/digitization-moreefficient.html (accessed on 4 January 2022).

37. Zeng, Y.; Jia, F.; Wan, L.; Guo, H. E-commerce in agri-food sector: A systematic literature review. Int. Food Agribus. Manag. Rev. 2017, 20, 439-460. [CrossRef]

38. Iyer, K.N.; Germain, R.; Claycomb, C. B2B e-commerce supply chain integration and performance: A contingency fit perspective on the role of environment. Inf. Manag. 2009, 46, 313-322. [CrossRef]

39. Todorovic, V.; Maslaric, M.; Bojic, S.; Jokic, M.; Mircetic, D.; Nikolicic, S. Solutions for More Sustainable Distribution in the Short Food Supply Chains. Sustainability 2018, 10, 3481. [CrossRef]

40. Himanen, S.J.; Rikkonen, P.; Kahiluoto, H. Codesigning a resilient food system. Ecol. Soc. 2016, 21, 21. [CrossRef]

41. Enthoven, L.; Van den Broeck, G. Local food systems: Reviewing two decades of research. Agric. Syst. 2021, $193,103226$. [CrossRef]

42. Peterson, H. Strategic choice along the vertical coordination continuum. Int. Food Agribus. Manag. Rev. 2001, 4, 149-166. [CrossRef]

43. Leonardo, W.J.; Bijman, J.; Slingerland, M. The Windmill Approach. Outlook Agric. 2015, 44, 207-214. [CrossRef]

44. Renting, H.; Marsden, T.K.; Banks, J. Understanding Alternative Food Networks: Exploring the Role of Short Food Supply Chains in Rural Development. Environ. Plan. A 2003, 35, 393-411. [CrossRef]

45. Marsden, T.; Banks, J.; Bristow, G. Food Supply Chain Approaches: Exploring their Role in Rural Development. Sociol. Rural. 2000, 40, 424-438. [CrossRef]

46. Eriksen, S.N. Defining local food: Constructing a new taxonomy-Three domains of proximity. Acta Agric. Scand. Sect. B Soil Plant Sci. 2013, 63, 47-55. [CrossRef] 